\title{
Development of '16-Holes Manual Dexterity Pegboard' and the Normal Value of 6 Years Old Children
}

Fanny Aliwarga, Ferial Hadipoetro, Angela BM Tulaar, Surjanto H

Faculty of Medicine - University of Indonesia, Jakarta, Indonesia

\begin{abstract}
Objectives: Obtaining the standard normal value of 6 years old children aged six year, and testing our hypothesis if girls' dexterity is higher than boys.

Methods: The design of this study was a cross sectional study of six years old students of public elementary school in South Jakarta. Inclusion criteria included age six years old, no neurological and orthopedic problem, normal nutritional status and right handed. Location based-random sampling was performed. Dependent variables comprised of age, sex and nutritional status. Independent variable was the result of '16-Holes Three-Jaw Chuck Manual Dexterity Pegboard' test. Statistical analysis was done by descriptive analysis and Mann Whitney Test.

Results: There were 191 girls and 191 boys who fulfilled the criteria. The '16-Holes Three-Jaw Chuck Manual Dexterity Pegboard' test allowed subjects to be assessed for their ability to put numbers of peg within 15 seconds. The mean number of pegs placed for girls was 6.92 pegs (CI 95\% 6.76-7.08) and boys was 6.49 pegs (CI 95\% $6.33-6,65$ )
\end{abstract}

Conclusions: Girls are able to place more pegs than boys in a given time. Furthermore, girls' manual dexterity is superior to boys $(\mathrm{p} 0,000)$.

Key words: Manual dexterity, standard normal value, pegboard, sex differences

\section{INTRODUCTION}

The function of the upper extremity is very important to a successfully moving throughout the activities of the day. Take a moment to scan the activities you completed within the first hour after waking up in the morning, they probably included brushing your teeth, combing your hair. In reviewing the typical activities of the day, it becomes apparent that upper extremity

Received in March 2013 and accepted for published in April 2013.

Correspondence email: Fanny Aliwarga, avfannyaliwarga@yahoo.com function is the basis for fine motor skills and is very important for activities such as feeding, dressing and grooming. ${ }^{1}$ Other than for activities of daily living, the dexterity is used to accomplish school activities and playing. ${ }^{2}$ Dexterity is defined as adroitness and manual skill. $^{3}$

Although it has been reported that $10 \%$ of school-age children have difficulty with dexterity tasks, fine motor dexterity screening is not routinely performed for school age children. Smith et al suggested that one explanation may be the lack of a simple and easy tool for screening and proposed that pegboard test may 
be an appropriate screening tool. ${ }^{4}$

A lot of pegboard available in primary school or in the market in Indonesia but they have not complied with the standard normal value. The need to get the standard normal value that fit with local situation is very important as a screening for children's upper extremity. Many pegboard test also found that dexterity in girls ouperformed boys. Therefore, the purpose of this study is to get the standard normal value for six years old children and to know the difference of dexterity between girls and boys

\section{Definition}

Dexterity refer to adroitness and skill in bodily movements, including manipulative skills and the ability to regulate control mechanisms. ${ }^{3}$ It depends on powerful, distributed neural networks and includes two concepts of speed and accuracy. ${ }^{5}$ Full achievement of bimanual and skillful manipulations usually takes six or more years and is typically referred to as dexterity. ${ }^{6}$

\section{Components of Dexterity}

Components of dexterity are reach, grasp, carry and release. Reaching is the directing or adjusting of the hand toward an object., ${ }^{2,7}$ Rosbald states that in a reaching movement the goal is to transport the hand to the target, with precision in both the time and space. ${ }^{2}$

Grasp is the attainment the object on the hand by closing it., ${ }^{2,7}$ Napier (1956) proposed two basic terms to describe hand movement : dexterity and non-dexterity. Non-dexterity movements involve pushing or lifting the object with the fingers or the entire hand. In contrast, dexterity movements involve grasp of an object and may be further divided according to purpose of grasp: precision grasp/pinch or power grasp/ palmar grasp. $^{2}$

Precision grasp/pinch involve opposition of the thumb to fingertips. ${ }^{2}$ Examples of precision grasp/pinch include pad-to-pad pinch or two-point pinch or pincer grasp, three-point pinch or three-jaw chuck, tip-to-tip pinch and pad-to-side atau lateral pinch. . $^{2,7}$

Pad-to-pad pinch or two-point pinch is opposition of the thumb to the index finger pad. Three-point pinch or three-jaw chuck is opposition of the thumb simultaneously to the index and middle finger pads. ${ }^{2}$ Seventy percent of dexterity activity is carried out by variants of this position. ${ }^{8}$ Tip-to-tip pinch is opposition of the thumb tip and index fingertip so that a circle is formed. Pad-to-side atau lateral pinch is used to exert power on or with a small object. ${ }^{2}$

Power grasp/palmar grasp are defined as forcible activities of the fingers and thumb that act againts the palm to transmit a force to an object. ${ }^{78}$ Power grasp/palmar grasp is divided into cylindric grasp, spheric grasp, hook grasp and disc grasp. ${ }^{2,7}$ Power grasp is used in its various modifications for about $20 \%$ of activities. $^{8}$

Carrying is transportation of a handheld object from one place to another. Release is the process of letting go of a hand-held object at a spesific time and place., ${ }^{2,7}$

\section{Sequential Development of Grasp}

The following sequence is typical during the infant's first 6 months. Initially the infant has no voluntary hand use. The hands alternately open and close in response to varoius sensory stimuli. Gradually, the traction response and grasp reflex decrease and a voluntary ulnar grasp begin to emerge. By approximately 6 months, the infant progresses to being able to use a palmar grasp. ${ }^{2}$

The second 6 months is a key period for development of hand skills. The ability to grasp a variety of objects increases significantly between 6 and 9 months of age. Crude raking of tiny object is present by about 7 months of age and by 9 months of age, the infant is able to attain a tiny object on the finger surface and with the thumb. However, with larger objects the infant's grasp is much more mature. By 8 to 9 months of age the infants holds an object between the thumb and the two radial fingers (i.e., uses a radial digital grasp) and readily varies the grasping pattern according to the shape of object. Between 9 and 12 months of age, refinement occurs in the ability to use thumb and finger pad control for tiny and small objects. $^{2}$

After 1 year of age, further refinement occurs in grasp patterns that were seen earlier and more sophisticated patterns emerge. Between 12 and 15 months of age the infant's 
ability to hold flat objects (cookies) identifies an increasing control of the intrinsic mucles. Between 18 months and 3 years of age most children with typical development acquire the ability to use a disc grasp, a cylindrical grasp and a spherical grasp with control. The pattern for lateral pinch may be present by 3 years of age. Overall grasp patterns for a variety of objects is well developed by 5 years of age. ${ }^{2}$

\section{Contribution of Other Performance Components to Dexterity}

As children mature, they begin to effectively coordinate visual skills with hand skills, and later they combine hand-eye coordination with visual perceptual skills. Although practitioner usually give motor issues the most attention, many dimensions of development significantly influence effective hand use, including the child's visual skills, somatosensory function, sensory integration, visual perception, cognition, social factors and culture. ${ }^{2}$

\section{Attention Development}

Attention is an ability to select and attend to a spesific stimulus while simultaneously supressing extraneous stimuli. ${ }^{10}$ A normal attention span is 3 to 5 minutes per year of child's age. Therefore, a 2 year-old should be able to concentrate on a particular task for at least 6 mintes and as child entering kindergarten should be able to concentrate for at least 6 mintes. ${ }^{11}$

\section{Hand Dominance}

Hand dominance is the consistent use of one hand over the other for such tasks as throwing a ball, writing with a pencil and eating with a fork. The preschool child develops a hand preference as he or she practices skilled tasks such as eating with utensils, coloring and throwing a ball. By 4 to 6 years, hand preference is well established. Lateralization of the brain, or the process in which the hemispheres become specialized for particular functions, is generally thought to be the the driving force behind hand dominance. By 6 to 7 years, laterality is demonstrated by concistent and superior use of one hand over the other to hold a pencil during writing tasks. ${ }^{7}$

The superior performance of the dominant hand over the non-dominant hand in most tasks has been documented extensively. In particular, the dominant hand is faster and more accurate than the non-dominant one. ${ }^{12}$

\section{Pegboard Test}

Pegboard test is a simple and easy tool for dexterity screening ${ }^{4}$. Many source recommended pegboard test as a routine measure of dexterity. ${ }^{4,14,15,13,16,17,18,19,20,21,22,23,24}$ National Children's Study recommended pegboard test as a part of routine neuropsychological assessment at age 3-6 years old. ${ }^{17}$ Gardner considers thet pegboard test provides an excellent test of fine motor coordination in children with neurologically based developmental disabilities, wherease according to Spreen and Staruss, this instrument is used mainly to measure finger and and hand dexterity. ${ }^{14}$

\section{Sex Differences in Brain Development and Dexterity}

Female and male brain differ. Differences begin early during development due to a combination of genetic and hormonal events and continue throughout the lifespan of an individual. ${ }^{25}$

Many study show that in pegboard test, score tended to increase with significant differences as the age increases in both males and females and girls outperformed boys. ${ }^{4,5,14}$ This is fit with hypothesis that women tend to better then men in performing certain manual task, such as placing pegs in designated holes on a board. ${ }^{26}$ Women have perceptual speed, for instance in matching items is better, and so is their manual precision. ${ }^{27}$

\section{METHODS}

Design of this study was cross sectional study. Target population were six years old children in public elementary school in South Jakarta. Sampling was done by 2 -stage randomization for location followed by randomization on site with probability proportional to size.

Inclusion criteria were children 6 years old (boys and girls) in public elementary school in South Jakarta, no neuro-musculosceletal 
abnormality proved by pegboard test trial, normal nutrition criteria by Epi Info (z-skor weight/height $-2 \mathrm{~s} / \mathrm{d}+2$ ). Exclusion criteria were children with parent-reported or self-reported history of neurological or orthopaedic disability, visual problem, not attending when the test is done and left-handed children.

Participants were 382 children age 6 years old (191 girls and 191 boys) from 9 public elementary school in 3 distric in South Jakarta. Dependent variables were age, sex and nutritional status. Independent variable was the score on 16-holes Three-Jaw Chuck Manual Dexterity Pegboard Test. Statistical analysis was done by descriptive analysis and Mann Whitney Test.

This study using pegboard and pegs that was made by researchers as a modification of 100-holes wooden pegboard. This pegboard made from dark brown wooden, size $9 \times 19.5 \times 2.5$

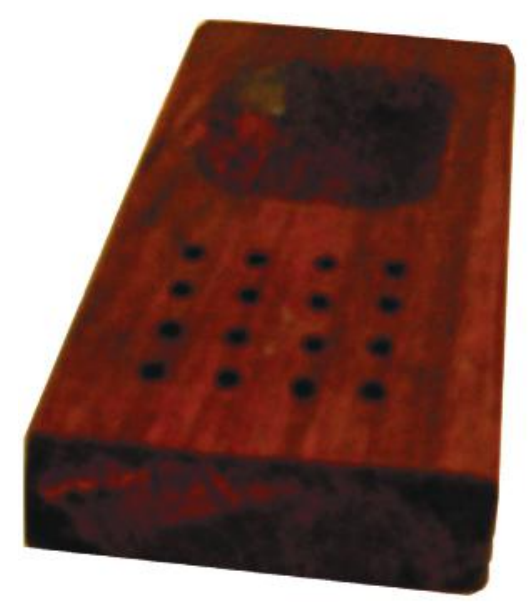

Picture 2. Pegboard

\section{RESULTS}

There are 10 districts in South Jakarta and 3 districts were chosen through simple randomization (Kebayoran Baru District, Pesanggrahan District and Setiabudi District). In each district, we made a list of public elementary school and we chose 3 school in each district by simple randomization. For each school, we made a list of 6 years old children. $\mathrm{cm}$. This pegboard has 16 holes, arranged in 4 rows and 4 column. Each hole has a distance $1 \mathrm{~cm}$ with diameter hole is $0.5 \mathrm{~cm}$ and $1 \mathrm{~cm}$ depth. At the upper part of pegboard, there is a hole size $4.5 \times 8 \times 2 \mathrm{~cm}$ to put all the pegs. This pegboard is named 16-holes Three-Jaw Chuck Manual Dexterity Pegboard (picture 2). Peg is a cylindrical-shaped thing, made from wood and red painted with diameter $0.4 \mathrm{~cm}$, length $4 \mathrm{~cm}$ (picture 3)

The parents of participant were told about the procedure and asked for the permission. At the time of the test, the child had a general physical examination. The child were instructed by the same person and with the same instruction. Participants were asked to insert as many pegs as they can in 15 second and they only allowed picking 1 peg at a time. Subjects completed one-practice trial followed by the actual test.

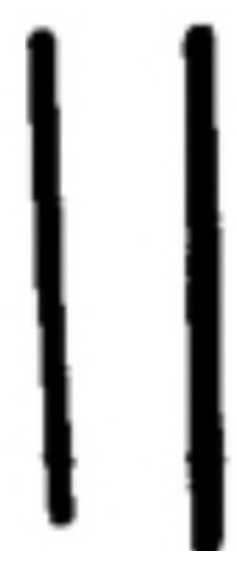

Picture 3. Pegs

This list were adjusted to the inclusion and exclusion criteria. From the last list, we did a simple randomization to choose the participant that would be included in this test.

The means and standard deviations according to gender are shown in table 1 and 2. All subjects had the same age (6 years old, 72-84 months), with normal nutritional status criteria according to Epi Info (z-skor weight/ height $-2 \mathrm{~s} / \mathrm{d}+2$ ), and were right handed without neurological or orthopaedic disability. 
Table 1. Characteristic of Subjects

\begin{tabular}{|c|c|c|c|c|}
\hline & Mean & Standard Deviation & Minimum & Maximum \\
\hline \multicolumn{5}{|l|}{ Girls } \\
\hline Age (months) & 78.9 & 3.2 & 72 & 84 \\
\hline Weight (kg) & 19.9 & 2.9 & 15 & 31 \\
\hline Height $(\mathrm{cm})$ & 116.07 & 4.84 & 104.50 & 129.30 \\
\hline Z-Score Weight/Height & -0.37 & 0.92 & -1.99 & 1.97 \\
\hline \multicolumn{5}{|l|}{ Boys } \\
\hline Age (months) & 79.5 & 3.18 & 72 & 84 \\
\hline Weight (kg) & 20.4 & 3.1 & 15 & 32 \\
\hline Height $(\mathrm{cm})$ & 116.87 & 5.05 & 104.50 & 130 \\
\hline Z-Score Weight/Height & -0.49 & 0.91 & -2.00 & 1.90 \\
\hline
\end{tabular}

Means, standard deviations and 95\% CI of pegs inserted by girls and boys are shown in table 3. To know the statistical difference of means pegs inserted by girls and boys, a Mann-
Whitney test was done and the result showed a very significant difference between mean of girls and boys $(\mathrm{p} 0,000)$ (picture 4$)$

\begin{tabular}{lrcrc}
\hline \multicolumn{1}{c}{ Pegs Inserted } & \multicolumn{2}{c}{ GIRLS } & BOYS \\
\hline & Statistic & Standard Error & Statistic & Standard Error \\
\hline Mean & 6.92 & 8.095 E-02 & 6.49 & 8.128 E-02 \\
95\% Confidence Interval & & & \\
For Mean & & & \\
$\quad$ Lower Bound & 6.76 & 6.33 \\
Upper Bound & 7.08 & 6.65 \\
Median & 7.00 & 6.00 \\
Standard Deviation & 1.12 & 1.12 \\
Minimum & 4.00 & 4.00 \\
Maximum & 10.00 & 10.00 \\
Range & 6.00 & 6.00 \\
\hline
\end{tabular}

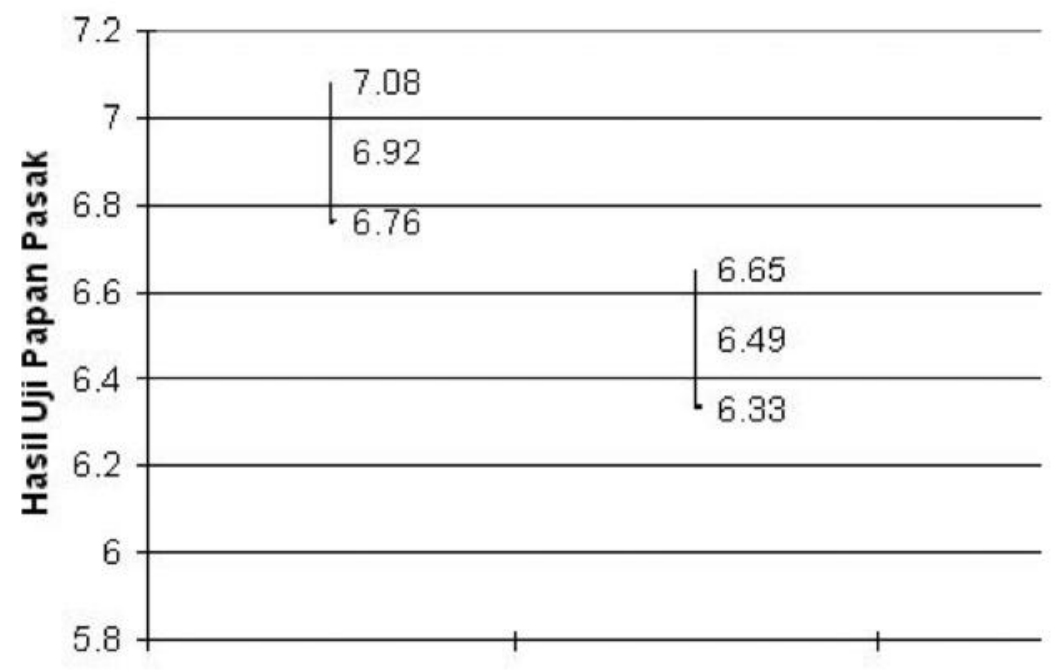

Picture 4. Means and 95\% CI for girls and boys 


\section{DISCUSSION}

In general population, $85-80 \%$ people is right handed and $10-15 \%$ is left handed. ${ }^{4}$ Subsequent analyses indicated that differences in lateralization were significant or near significant in the 5 and 7 years old. By 9 years of age, rightand left-handed subjects no longer differed in the degree of laterality. ${ }^{13}$ Those data are the basis so in this study conducted only with right hand in right-handed children.

This study used a modification of the 100-holes wooden pegboard. There are only 16 holes in this pegboard as the preliminary study showed that children and adult can only insert 4-13 pegs in 15 seconds. This pegboard has already passed the reliability test in that preliminary study.

Reiss et al investigate normal children between 5-17 years old. They found that in overall male's brain size having, on average, a greater $10 \%$ volume than female. Their study strongly suggests the presence of early genderassociated differences in cerebral development and organization, also increased of cortical grey matter was the most consistent contributor to brain volume difference between male and female. ${ }^{28}$ In neurobiology in its broadest context, one must assume that there is a functional and/ or structural sexual dimorphism until proven otherwise. The brains of men and women and boys and girls do differ to a degree. Overall, the similarities between their brains are most obvious, but sexual dimorphisms in discrete regions of the brain exist and are likely to have significant functional consequences. ${ }^{29}$

The corpus callosum is enlarged in female, compared to male and female has a greater axonal density. ${ }^{27,30,31}$ The result of difference in the corpus callosum are said to result in a greater relative fluency of thought and speech. Anterior commisure, structure that connects between the cerebral hemispheres and communicates visual, olfactory and auditory information is also larger in female than in male. ${ }^{27}$

Excellence in visual-spatial tasks and mathematical reasoning or verbal tasks may be determined very early in life by hormones through their effects on neuronal growth and synaptic connections. ${ }^{29}$ Androgen in male is proved to develop masculine pattern, that is in improvement in certain spatial task over verbal fluency. In female, verbal fluency and dexterity is better because higher estrogen level. Male is better in visuo-spatial tasks because better development of right hemisphere. ${ }^{26}$

This study showed that girls performed very significantly better than boys. This result was similar to the previous dexterity study by Poole et al, ${ }^{4}$ Brito and Santos-Morales, ${ }^{14}$ Deasi et al, ${ }^{23}$ Schmidt et al, ${ }^{20}$ and also Ruff and Parker ${ }^{24}$ and conclusion in this study supported the conclusion of the previous studies.

Poole et al investigated dexterity in children aged 4-19 years (213 girls and 193 boys) using the Nine-hole Peg Test. Subjects were asked to place all the pegs in holes and then all the pegs were put back to its container. Time to insert and put back was recorded. In all age groups, girls performed faster than boys. ${ }^{4}$

Brito and Santos-Morales (2002) developed norms for Purdue Pegboard in Brazil. Sample study were 346 children (173 girls and 171 boys) aged 5.0-15.11 years (mean age of 9.4 years, SD 2.76). The result showed that girls had better score for variable number of pegs placed with the dominant hand, nondominant hand and both hands. According to them, there seems to be a differential rate of neuropsychological development for boys and girls in the sense that girls usually outperform boys in most assessment instrument. On molecular level, it may be suggested that the better neuropsychological performance of girls is related to developmental differences between the sexes in basic mechanisms of neuronal plasticity in the brain. Furthermore, differences in neuropsychological performance between boys and girls may depend on the extend of recruitment of populations of cortical neurons likely to be selectively activated during the planning and execution of a particular behavioral task. It can be surmised that sex differences in the development of neuropsychological functions depend on genetic factors (e.g., hormones) impinging upon the brain during neural development. ${ }^{14}$

Desai et al (2006) collected normative value of Purdue Pegboard on India population 
age group 5-65 years old. This study was conducted on 600 subjects. For age range 5-15 years old, means normal standard value between girls and boys were the same, 15 pegs (SD 2) ${ }^{23}$ Range of age of this study is too wide with too little sample to develop norms.

Schmidt et al (2000) studied performance on the Grooved Pegboard Test in adult, 25 females (17-24 years old) and 27 males (18-26 years) to know the effect of gender to the result. This study confirmed previous findings that gender is a significant predictor of performance if using dominant hand $(\mathrm{p}<0.01)$, however, reported that finger size accounted for sex differences in pegboard performance. According to these authors, females are faster because their small fingers allow them to pick up and handle the pegs more easily than males. ${ }^{20}$

Ruff and Parker (1993) did a research to develop normative values for Grooved Pegboard Test aged range from 7-22 years. A converse gender difference was noted, since women were substantially faster than men. ${ }^{24}$

Other than pegboard test, females were proven to be faster than males in other tests that need speed and accuracy. Amirjani (2007) did a study to examine the impact of gender on performance of the Moberg Pick-Up Test in 116 healthy subjects (87 females and 29 males). Women accomplished the test faster than males. ${ }^{32}$

\section{CONCLUSIONS}

This study used a 16-holes Three-Jaw Chuck Manual Dexterity Pegboard, modified by the researcher from the pegboard available in the market. The means of pegs inserted was 6,92 (SD 1,12) for girls and 6,49 (SD 1,12) for boys. The Mean number of pegs for girls is very significantly higher than for boys ( $p 0,000)$.

\section{REFERENCES}

1. Shumway-Cook A, Woollacott MH. Normal Reach, Gasp And Manipulation. In: Shumway-Cook A, Woollacott $\mathrm{MH}$, editors. Motor Control: Theory And Practical Applications. $1^{\text {st }}$ ed. Philadelphia:
Lippincott Williams And Wilkins; 2001. p.447-70.

2. Exner CB. Development Of Hand Skills. In: Case-Smith J, editor. Occupational Therapy For Children. $4^{\text {th }}$ ed. Philadelphia: Mosby; 2001. p.289-328.

3. WHO.International Classification Of Impairments, Disabilities And Handicap. 1980.

4. Poole JL, Burtner PA, Torres TA, McMullen CK, Markham A. Measuring Dexterity In Children Using The Nine-hole Peg Test. J Hand Ther. 2005 Jul-Sep;18:348-51.

5. Nandgaonkar HP. Rivet And Eyelet Deftness Test (Red Test) : A Measure For Hand Dexterity. The Indian Journal Of Occupational Therapy. 2002 AprilJuly;XXXIV:1;13-22.

6. Wiesendager $M$, Seriien DJ. Toward A Physiological understanding Of Human Dexterity. News Physiol Sci.2001 October;16:228-235.

7. Duff SV. Prehension. In: Cech D, Martin ST, editors. Functional Movement Development Across The Life Span. $1^{\text {st }}$ ed. Pensyllvania: WB Saunders Company;1995.p.313-51.

8. Kottke FJ. Therapeutic Exercise To Develop Neuromuscular Coordination. In: Kottke FJ, Lehmann JF, editors. Krusen's Handbook Of Physical Medicine And Rehabilitation. $4^{\text {th }}$ ed. Philadelphia: WB Saunders; 1990.p.452-79.

9. Stott LH. The Motor Functions. In: Stott LH, editor. Child Development An Individual Longitudinal Approach. USA: Hold, Rinchart And Winston Inc;1967. p.119-53.

10. Unsworth C, Warburg CL. Assessment And Intervention Strategies For Cognitive And Perceptual Dysfunction. In: O'Sullivan SB, Schmitz TJ, editors. Physical Rehabilitation: Assessment And Treatment. $4^{\text {th }}$ ed. Thailand: FA Davis Company; 2001. p.961-992.

11. Schmitt BD. Dealing with ADHD. University Of Minnesota Children Hospital. 2005. Available from : www. uofmchildrenshospital.org/library/content/ pa_battentn_hhg.htm

12. Ozcan A, Tulum Z, Pinar L, Baskurt F. 
Comparison Of Pressure Pain Threshold, Grip Strenght, Dexterity And Touch Pressure Of Dominant And Non Dominant Hands Within And Between Right And Left Handed. J Korean Med Sci. 2004; 19:8748.

13. Mandell RJ, Nelson DL, Cermak SA. Differential Laterality Of Hand Function In Right-Handed And Left-Handed Boys. Am J Occup Ther. 1984 Feb;38(2):114-20.

14. Brito GNO, Santos-Morales TR. Developmental Norms For The Gardner Steadiness Test And The Purdue Pegboard : A Study With Children Of A Metropolitan School In Brazil. Braz J Med Bio Res. 2002;35(8):931-49.

15. Garry MI, Kamen G, Nordstrom MA. Hemispheric Differences In The Relationship Between Corticomotor Exitability Changes Following A FineMotor Task And Motor Learning. J Neurophysiol. 2004;91:1570-8.

16. Judge J, Stirling J. Fine Motor Skill Performance. In Left- And Right-Handers: Evidence Of An Advantage For LeftHanders. Laterality. 2003 Oct;8(4):297306.

17. White RF. Neuropsychological Assessments in Children From A Longitudinal Perspective For the National Children's Study. Prepared for the National Children's Study by Battelle Memorial Institute. 2004. Report No.: 282-98-0019.

18. Wade DT. Measurement In Neurological Rehabilitation. $1^{\text {st }}$ ed. New York: Oxford University press Inc; 1992.p.105.

19. Bryden PJ, Roy EA. A New Method Of Administering The Grooved Pegboard Test: Performance As A Function Of Handedness And Sex. Brain Cogn. 2005;58: 258-268.

20. Schmidt SL, Oliveira RM, Rocha FR, Abreu-Villaca Y. Influences Of Handedness And Gender On The Grooved Pegboard Test. Brain Cogn. 2000 Dec;44(3):445-54.

21. Bruininks RH. Manual Bruininks-Oseretsky Test Of Motor Proficiency. USA. American Guidance Service Inc.1978.

22. Neuropsychological Assessment. Available from : schatz.sju.edu/neuro/npsych/npsych. html
23. Desai K, Kene K, Doshi M, More S. Normative data of Purdue Pegboard on Indian Population. The Indian Journal Of Occupational Therapy. Dec 05-March 06;37(3): 69-72.

24. Ruff RM, Parker SB. Gender- And AgeSpecific Changes In Motor Speed And EyeHand Coordination In Adults: Normative Values For The Finger Tapping And Grooved Pegboard Tests. Percept Mot Skills. 1993 Jun;76(3 Pt 2):1219-30.

25. Becker JB, Arnold AP, Berkley KJ, Balustein JD, Eckel LA, Hampson E, HermanJP, Marts S, Sadee W, Steiner M, Taylor J, Young E. Strategies And Methods For Research On Sex Differences In Brain And Behavior. Endocrinology. 2005;146(4):1650-73.

26. Kimura D. Sex, Sexual Orientation And Sex Hormone. Available from: www.sfu. ca/ dkimura/articles/sex.htm

27. Sex differences. Available from: http:// www.gender.org.uk/about/07neur/77_diffs. $\mathrm{htm}$

28. Reiss AL, Abrams MT, Singer HS, Ross JL, Denckla MB. Brain Development, Gender And IQ In Children A Volumetric Imaging Study. Brain. 1996;119:1763-74.

29. Gorski R. Development Of The Cerebral Cortex: XV. Sexual Differentiation Of The Central Nervous System. J Am Acad Child Adolesc Psychiatry. 1998;37(12):1337-9.

30. Sabbatini RME. Are There Difference Between The Brains Of Males And Females. Available from : www.cerebromente.org. br/n11/mente/eisntein/cerebro-homens. $\mathrm{html}$

31. Highley RJ. Esiri MM, McDonald B, Cortina-Borja M, Herron BM, Crow TJ. The Size And Fibre Composition Of The Corpus Callosum With Respect To Gender And Schizophrenia: A Post Mortem Study. Brain 1999 Jan; 122 (Pt 1): 99-110.

32. Amirjani N, Ashworth NL, Gordon $\mathrm{T}$, Edwards DC, Chan KM. Normative Values And The Effects Of Age, Gender, And Handedness On The Moberg PickUp Test. Muscle Nerve 2007; Available from : http://www3.interscience.wi;ey. com.ezproxy.lib.monash.edu.au/cgi-bin/ help?page=HEP_syndication\#RSS 